\title{
Common and unique associations of adolescents' affective and cognitive empathy development with conflict behavior towards parents
}

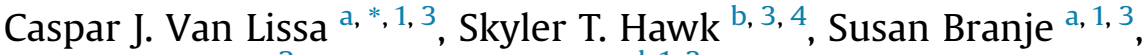 \\ Hans M. Koot ${ }^{\text {c, } 2}$, Wim H.J Meeus ${ }^{\text {a, d, } 1,3}$ \\ a Adolescent Development, Utrecht University, Heidelberglaan 1, 3584 CS Utrecht, The Netherlands \\ b The Chinese University of Hong Kong, Ho Tim Building, Chung Chi Rd, Shatin NT, Hong Kong \\ ${ }^{\mathrm{c}}$ VU University, Amsterdam, Van der Boechorststraat 1, 1081 BT Amsterdam, The Netherlands \\ d Developmental Psychology, Tilburg University, The Netherlands
}

\section{A R T I C L E I N F O}

\section{Article history:}

Available online $\mathrm{xxx}$

\section{Keywords:}

Empathy

Perspective taking

Conflict resolution

Adolescence

Longitudinal

\begin{abstract}
A B S T R A C T
Adolescents' development of two empathy dimensions, affective empathic concern and cognitive perspective taking, may be associated with shifts towards more constructive behaviors in conflict with parents. This six-year longitudinal study (ages 13-18) used multivariate latent growth curve modeling to investigate correlations between the developmental trajectories of adolescents' $(N=497)$ empathic dispositions and trajectories of their conflict behaviors towards both parents. There were some similarities between the associations of both empathy dimensions with conflict behaviors. Both empathy dimensions were associated with reduced conflict escalation with mothers, and increased problem solving with both parents. However, these associations were consistently stronger for perspective taking than for empathic concern. Furthermore, higher levels of compliance with mothers in early adolescence were uniquely associated with over-time increasing empathic concern. Perspective taking was uniquely associated with decreased withdrawal from conflicts. Perspective taking thus appears to be more strongly associated with a pattern of constructive conflict behaviors.
\end{abstract}

() 2015 The Foundation for Professionals in Services for Adolescents. Published by Elsevier Ltd. All rights reserved.

Parent-child conflict is a natural part of adolescence, as youths endeavor to forge their own identities in the context of continued closeness with their parents (Laursen \& Collins, 2004). Such conflicts are not inherently harmful; what is more important is the way adolescents learn to manage these conflicts (Branje, Van Doorn, Van der Valk, \& Meeus, 2009). The obligatory and permanent nature of the adolescent-parent relationship provides a context for adolescents to practice adaptive conflict resolution skills (Adams \& Laursen, 2001). It is important to study factors which might promote constructive

\footnotetext{
* Corresponding author. Department of Sociology, Erasmus University Rotterdam, The Netherlands. Tel.: +31 638126513.

E-mail addresses: vanlissa@fsw.eur.nl, c.j.vanlissa@uu.nl (C.J. Van Lissa), edpsy@fed.cuhk.edu.hk (S.T. Hawk), j.m.koot@vu.nl (H.M. Koot).

1 Tel.: +31302534601.

2 Tel.: +31205988740

3 SecretariaatPedagogiek@uu.nl.

4 Tel.: +85239436904 .
} 
adolescent-parent conflict resolution, because conflict behaviors towards parents spill over into adolescents' conflict behaviors with peers, and are thought to shape models for future conflict resolution with romantic partners (e.g., see Markiewicz, Lawford, Doyle, \& Haggart, 2006; Van Doorn, Branje, Van der Valk, De Goede, \& Meeus, 2011). Adolescents' naturally occurring empathy development might be associated with a shift towards more constructive conflict behavior towards parents, because empathy decreases aggression, and increases pro-social behavior (Eisenberg \& Miller, 1987; Miller \& Eisenberg, 1988). Furthermore, empathy encompasses both affective and cognitive dimensions (e.g., Davis, 1983). Many interventions aim to promote the development of one or both of these dimensions in adolescents (Feshbach \& Feshbach, 2011). However, little is known about the common and unique associations that these dimensions might hold with specific conflict resolution behaviors. The present six-year longitudinal study addressed these issues by investigating whether the development of adolescents' affective and cognitive empathy is associated with common and unique changes in their conflict behaviors towards parents over time.

Previous research has identified specific conflict resolution behaviors, such as conflict escalation (intensifying the conflict and losing control), problem solving (negotiating a compromise), compliance without defending one's own position, and withdrawal from the discussion (Kurdek, 1994). The conflict resolution behaviors adolescents use with parents are associated with concurrent and future adjustment. For example, conflict escalation and withdrawal have been associated with internalizing and externalizing problems (Branje et al., 2009; Rubenstein \& Feldman, 1993; Van Doorn, Branje, \& Meeus, 2008). Problem solving, in contrast, was associated with lower levels of problem behavior. Interestingly, a person-centered analysis found that some adolescents engaged in compliance in concert with constructive problem solving, whereas others engaged in compliance alongside more negative behaviors like escalation and withdrawal (Branje et al., 2009). Conflict only predicted greater internalizing problems for the latter group, which suggests that compliance can be associated with either positive or negative developmental outcomes, depending on the context in which it occurs. Overall, these studies suggest that conflict escalation and withdrawal are associated with adolescents' poorer adjustment, when compared to constructive problem solving. It is therefore important to identify dispositional factors associated with a transition towards constructive conflict resolution behaviors during adolescence.

\section{Empathy and conflict resolution behavior}

The development of two specific empathy dimensions, empathic concern and perspective taking (Davis, 1983), appears to coincide with parallel developmental changes in adolescents' conflict behavior toward parents. Empathic concern involves sympathetic affective responses to the emotions of others (Eisenberg, 2000). Cognitive perspective taking involves the tendency to consider different sides of a dilemma. On average, empathic concern and perspective taking increase throughout adolescence, although empathic concern appears to stabilize at an earlier age (Eisenberg, Cumberland, Guthrie, Murphy, \& Shepard, 2005; Van der Graaff, De Wied, Hawk, Van Lier, \& Meeus, 2014). This empathy development is mirrored by a shift in adolescents' conflict behavior towards parents, from predominantly negative exchanges that culminate in compliance by one party, to greater constructive problem solving and negotiation of compromises (Laursen, Finkelstein, \& Betts, 2001; Van Doorn, Branje, \& Meeus, 2011). Such developmental parallels might be a manifestation of changes in shared neurological circuits. A network involving the prefrontal cortex and amygdala is central in empathic responding (Frith \& Frith, 2006; Singer, 2006), as well as conflict-related behavior (Blair, 2004). In adolescence, maturation of the prefrontal cortex leads to increased efficiency of perspective taking (Choudhury, Blakemore, \& Charman, 2006). Meanwhile, strengthening functional connections between the prefrontal cortex and amygdala foster the development of emotion regulation abilities (Gee et al., 2013), which is likely to result in more constructive conflict resolution behaviors. Empirical evidence for parallel development of empathy and conflict behavior within individuals is lacking, however, because developmental studies to date have not jointly investigated empathy and conflict behavior. To bolster the argument for developmental synchronicity, the present study aims to make the critical contribution of examining parallel development of empathic dispositions and specific conflict behaviors within individuals over time.

Empathic concern and perspective taking are likely to have common and unique associations with specific conflict behavior. Regarding common associations, both empathic concern and perspective taking have been linked with reduced aggression (Miller \& Eisenberg, 1988; Richardson, Hammock, Smith, Gardner, \& Signo, 1994), and increased pro-social behavior (Eisenberg \& Miller, 1987; Galinsky, Maddux, Gilin, \& White, 2008). This suggests that, in conflicts with parents, both empathy dimensions might be associated with reduced escalation and increased constructive problem solving. However, these empathy dimensions are also likely to hold unique associations with specific conflict behaviors. Empathic concern rouses a motive to reduce others' distress (Stocks, Lishner, \& Decker, 2009), and might consequently increase adolescents' willingness to reduce parents' negative emotions by complying to their demands, even if that means they will lose ground in an argument. Perspective taking, on the other hand, might allow adolescents to take some emotional distance from the heat of a conflict, consider both sides of the argument, and engage in more constructive and mutually beneficial conflict behaviors (e.g., Sandy \& Cochran, 2000). However, the literature on adolescents has focused primarily on associations between affective empathy and conflict-related constructs, without taking into account potentially differential associations for cognitive empathy. For instance, adolescents' greater self-reported affective empathy was found to be associated with reduced conflict escalation and greater problem solving with peers (De Wied, Branje, \& Meeus, 2007). A study using peer-reported measures found similar associations, and additionally found that adolescents' affective empathy was associated with increased withdrawal (Björkqvist, Österman, \& Kaukiainen, 2000). Additional research is thus required to identify common and unique 
developmental associations between adolescents' affective and cognitive empathy and their conflict resolution behaviors towards parents.

Research on adults provides some support for common and differential associations of affective and cognitive empathy. For example, a correlational study on college students found that empathic concern was uniquely linked to elevated withdrawal and compliance in conflicts with friends, whereas perspective taking was associated with greater constructive problem solving with both friends and siblings (Richardson et al., 1994). Additional support comes from the experimental literature, which has provided causal evidence for differential effects of empathic concern and perspective taking on conflictrelated behavior. In negotiation experiments, perspective taking also helped participants reach mutually beneficial agreements with partners, and maximize both joint and individual gains, suggesting that they engaged in greater problem solving (Galinsky et al., 2008). Inducing empathic concern, while increasing interaction partners' satisfaction with the negotiation process, led to the poorest outcomes for participants, suggesting greater compliance. This interpretation is further supported by another finding that experimentally-induced empathic concern motivates participants to cooperate in prisoner's dilemma games, even when their opponent's previous defection meant that cooperation would likely undermine their own outcomes (Batson \& Ahmad, 2001).

If these aforementioned experimental and correlational findings can inform hypotheses about the associations between naturally occurring empathy development and changes in adolescents' conflict behavior, we might expect the development of both empathy dimensions to be associated with decreased conflict engagement. Both empathy dimensions are also likely to be associated with increased pro-social conflict behaviors, although adolescents' developing perspective taking is likely to be more positively associated with problem solving (Galinsky et al., 2008), and empathic concern is likely to be more positively associated with compliance (Björkqvist et al., 2000; Richardson et al., 1994). Finally, empathic concern is likely to be more positively associated with withdrawal than perspective taking.

\section{The role of parent and adolescent sex}

There are known differences between adolescents' relationships with mothers and fathers (see: Branje, Laursen, \& Collins, 2013) that may be reflected in the pattern of developmental associations between empathy and conflict behaviors. Mothers are more often the primary attachment figure than fathers (Markiewicz et al., 2006). Furthermore, adolescents typically enjoy higher quality relationships with mothers than with fathers, which are characterized by greater support (De Goede, Branje, \& Meeus, 2009), more shared activities, and expressions of emotion (Steinberg \& Silk, 2002). At the same time, conflict and expressed negativity are typically higher in relationships with mothers, particularly in mother-daughter relationships (see Branje et al., 2013; De Goede et al., 2009). Although this may seem paradoxical, these conflicts are often about everyday hassles (Laursen, 1995), and are thus particularly likely to arise in close relationships. This combination of elevated conflict frequency and greater closeness might make adolescent-mother relationships a more conducive environment for adolescents' empathic dispositions to be expressed in concrete conflict behavior than adolescent-father relationships. Consequently, developmental associations with adolescents' empathic dispositions might be more prevalent for conflict behavior towards mothers than towards fathers.

Adolescent sex is also known to play a role in the development of both empathy and conflict behavior. Girls are typically found to report higher levels of dispositional empathy than boys, especially when self-report measures are used (Eisenberg, Spinrad, \& Sadovsky, 2006). Moreover, research suggests that girls' empathic dispositions increase and stabilize at an earlier age than boys' (Van der Graaff et al., 2014), which is in line with girls' earlier pubertal development (e.g., Silberman \& Snarey, 1993). Evidence about sex differences in conflict behavior is less conclusive. Several studies have found that girls engage in more constructive conflict resolution with peers (Chow, Ruhl, \& Buhrmester, 2013; De Wied et al., 2007). However, it is unclear whether these findings also apply to adolescent-parent conflict, as others have reported that girls experience more frequent conflict with parents than boys, and that negativity is highest in mother-daughter conflicts (see Branje et al., 2013). Some researchers have reported that daughters are less avoidant regarding conflict (Laursen, 1995), whereas boys engage in greater withdrawal and compliance (Smetana, Daddis, \& Chuang, 2003; Vuchinich, 1987). By contrast, others have found that girls more often used conflict resolution styles characterized by high withdrawal than boys (Branje et al., 2009). To account for these known sex differences in development, we included adolescent sex as a covariate in all analyses. The mean-level differences in developmental trajectories for boys and girls are displayed in Table $1{ }^{4}$

\section{The present study}

This six-year longitudinal study examined whether developmental changes in adolescents' empathic concern and perspective taking were associated with changes in their conflict resolution behaviors with mothers and fathers. Although prior research indicates that empathy has correlational and causal links with conflict-related behaviors (Björkqvist et al., 2000; e.g., De Wied et al., 2007; Galinsky et al., 2008; Richardson et al., 1994), research to date has not investigated

\footnotetext{
${ }^{4}$ Although we found no prior literature to support such moderating effects, we explored potential sex moderation of the associations between empathic dispositions and conflict behaviors. These models had consistently worse fits compared to the final models reported in the paper, suggesting an absence of gender moderation.
} 
Table 1

Correlations between adolescent empathy and conflict behavior towards parents.

\begin{tabular}{|c|c|c|c|c|c|c|c|c|c|}
\hline & & \multirow[t]{2}{*}{$M$} & \multirow[t]{2}{*}{$s^{2}$} & \multirow[t]{2}{*}{$\operatorname{Sex}(B)$} & \multicolumn{2}{|l|}{ Intercepts } & \multicolumn{2}{|l|}{ Slopes } & \multirow{2}{*}{$\begin{array}{l}\text { Intercept of conflict } \\
\text { behavior }\end{array}$} \\
\hline & & & & & $\begin{array}{l}\text { Empathic } \\
\text { concern }\end{array}$ & $\begin{array}{l}\text { Perspective } \\
\text { taking }\end{array}$ & $\begin{array}{l}\text { Empathic } \\
\text { concern }\end{array}$ & $\begin{array}{l}\text { Perspective } \\
\text { taking }\end{array}$ & \\
\hline \multicolumn{10}{|l|}{ Intercepts } \\
\hline \multirow{2}{*}{ Escalation } & Mother & $1.61^{* * *}$ & $0.28^{* * *}$ & $0.12^{*}$ & $-.21^{* *}$ & $-.19 *$ & .01 & -.08 & \\
\hline & Father & $1.64^{* * *}$ & $0.26^{* * *}$ & $\quad 0.10^{*}$ & -.11 & $-.13 \dagger$ & -.05 & $-.17 \dagger$ & \\
\hline \multirow{2}{*}{$\begin{array}{l}\text { Problem- } \\
\text { solving }\end{array}$} & Mother & $3.03^{* * *}$ & $0.41^{* * *}$ & -0.10 & $.42^{* * *}$ & $.53^{* * *}$ & -.02 & .00 & \\
\hline & Father & $2.94^{* * * *}$ & $0.42^{* * *}$ & $-0.20^{* *}$ & $.44^{* * *}$ & $.49^{* * *}$ & -.07 & .15 & \\
\hline \multirow[t]{2}{*}{ Compliance } & Mother & $1.89^{* * *}$ & $0.15^{* * *}$ & -0.04 & -.05 & .05 & $.20^{*}$ & -.03 & \\
\hline & Father & $1.92^{* * *}$ & $0.16^{* * *}$ & * $\quad 0.00$ & .01 & .06 & .05 & -.07 & \\
\hline \multirow[t]{2}{*}{ Withdrawal } & Mother & $2.17^{* * *}$ & $0.27^{*}$ & 0.06 & -.11 & $-.19 *$ & -.14 & -.08 & \\
\hline & Father & $2.26^{* * *}$ & $0.21^{*}$ & 0.04 & -.18 & $-.23^{*}$ & -.01 & -.17 & \\
\hline \multicolumn{10}{|l|}{ Slopes } \\
\hline \multirow[t]{2}{*}{ Escalation } & Mother & $-0.02^{* * *}$ & $0.01^{* * *}$ & $\quad 0.02 \dagger$ & $.16 \dagger$ & $.15 \dagger$ & -.17 & $-.22^{*}$ & $-.49^{* * *}$ \\
\hline & Father & -0.01 & $0.01^{* * *}$ & 0.02 & -.06 & -.03 & .04 & -.01 & $-.36^{* * *}$ \\
\hline \multirow{2}{*}{$\begin{array}{l}\text { Problem- } \\
\text { solving }\end{array}$} & Mother & $0.02 *$ & $0.01^{* * *}$ & 0.02 & 0.00 & $-.18^{*}$ & $.26^{*}$ & $.50^{* * *}$ & $-.27^{* *}$ \\
\hline & Father & 0.01 & $0.01^{* * *}$ & $\quad 0.02$ & -.18 & $-.23^{*}$ & $.37^{* *}$ & $.41^{* * *}$ & $-.24^{*}$ \\
\hline \multirow[t]{2}{*}{ Compliance } & Mother & $-0.04^{* * *}$ & $0.01^{* * *}$ & $\quad 0.02$ & -.01 & -.05 & .03 & .09 & $-.40^{* * *}$ \\
\hline & Father & $-0.04^{* * *}$ & $0.01^{* * *}$ & 0.00 & -.08 & -.02 & .19 & $.22 \dagger$ & $-.42^{* * *}$ \\
\hline \multirow[t]{2}{*}{ Withdrawal } & Mother & $-0.05^{* * *}$ & $0.01^{*}$ & $0.04^{*}$ & -.07 & .06 & .20 & 0.00 & $-.44 \dagger$ \\
\hline & Father & $-0.04^{* * *}$ & $0.02^{* * *}$ & $0.04^{* *}$ & * $\quad .07$ & .03 & -.01 & .07 & $-.39 \dagger$ \\
\hline
\end{tabular}

$\dagger<.08$. Note. Sex differences refer to the mean difference between boys (0) and girls (1) in latent growth parameters. ${ }^{*} p \leq .05,{ }^{* *} p<.01,{ }^{* * *} p<.001$.

whether the natural development of adolescents' empathy is similarly associated with changing conflict behavior towards parents. More importantly, although many interventions promote either affective or cognitive empathy (see: Feshbach \& Feshbach, 2011), relatively little is known about their common and unique associations with different pro-social outcomes, such as constructive conflict behavior. Therefore, we set out to investigate the common and unique associations of adolescents' developing empathic concern and perspective taking with specific conflict behaviors towards parents. In order to investigate these questions of parallel development, we estimated developmental trajectories for both empathic dispositions and conflict resolution behaviors for each adolescent. Parallel development is reflected by correlations between the intercepts (initial level) and slopes (over-time change) of these trajectories. We predicted that greater levels and over-time change of both empathy dimensions would be associated with reduced conflict escalation. We further expected perspective taking to be more positively associated with problem solving than empathic concern, and empathic concern to be more positively associated with compliance and withdrawal than perspective taking.

\section{Methods}

\section{Participants and procedure}

Participants were 497 Dutch adolescents (282 boys; initial age $M=13.03, S D=0.46$ ), enrolled in an ongoing longitudinal study (Van Lier et al., unpublished manuscript). Adolescents were recruited from randomly selected schools in the province of Utrecht, and four main cities in The Netherlands. Of 1081 families contacted, 470 refused and 114 did not produce informed consent. Adolescents predominantly had a Dutch ethnic background (95\%), and most (88\%) came from mediumor high-SES families based on parents' reports of employment status (Statistics-Netherlands, 1993). Six annual measurement waves were conducted from 2006 to 2012. Trained interviewers administered questionnaires at home, which included the variables used in the present study. Adolescents received financial compensation for their participation at each wave (approximately \$40). The average participation rate across waves was $90.10 \%$, and 425 adolescents (85.50\%) were still involved in the study at Wave 6.

\section{Measures}

\section{Empathy}

We used two subscales of Davis' (1983) Interpersonal Reactivity Index (IRI), a widely used multi-dimensional self-report measure of empathy, to assess adolescents' empathic concern (EC; "I would describe myself as a pretty soft-hearted person") and perspective taking (PT; "I try to look at everybody's side of a disagreement before I make a decision"). Each subscale contained seven items, rated on a 5-point Likert scale ( $0=$ Doesn't describe me at all; $4=$ Describes me very well). The Dutch IRI has demonstrated adequate reliability and external validity in samples of adults and adolescents (De Corte et al., 2007; Hawk et al., 2013). In line with the recommendations of Revelle and Zinbarg (2009), we report both Cronbach's alpha, and McDonald's omega, because Cronbach's alpha is known to severely underestimate test reliability when scales are not strictly unidimensional. Omega reflects the proportion of test variance due to all common factors, and is interpreted the same as 
alpha. Reliability of empathic concern was acceptable in the first wave $\left(\alpha=.62, \omega_{\mathrm{t}}=.70\right)$ and good in all other waves ( $\alpha \mathrm{s}$ $\left..72-.76, \omega_{\mathrm{t}} \mathrm{s} .81-.85\right)$. Reliability for perspective taking was acceptable in waves one and two $\left(\alpha \mathrm{s}=.60\right.$ and $.67, \omega_{\mathrm{t}}=.70$ and $.78)$ and good in all other waves ( $\left.\alpha \mathrm{s} .75-.78, \omega_{\mathrm{t}} \mathrm{s} .87-.82\right)$.

\section{Conflict resolution styles}

Adolescents indicated how often they used four different conflict resolution styles towards each parent, using a Dutch adaptation of Kurdek's Conflict Resolution Styles Inventory (CRSI, Kurdek, 1994). This instrument distinguishes between conflict escalation ("Letting myself go, and saying things I do not really mean"), problem solving ("Trying to find solutions that are acceptable to both of us"), compliance ("Giving the other what he/she wants"), and withdrawal ("To stop responding and refuse to discuss the matter further"). Each conflict resolution style is assessed with five items, on a 5-point Likert scale ( 1 = Never; 5 = Always). Each style was assessed on a yearly basis, except withdrawal, which was omitted from the questionnaire in wave 2 and 3 to make place for measures unrelated to the present study. Reliability was good in all waves for escalation ( $\alpha \mathrm{s} .76-.85, \omega_{\mathrm{t}} \mathrm{s} .80-.92$ ), problem solving ( $\alpha \mathrm{s} .82-.89, \omega_{\mathrm{t}} \mathrm{s} .88-.91$ ), and withdrawal ( $\alpha \mathrm{s} .70-.89$, $\left.\omega_{\mathrm{t}} \mathrm{s} .76-.90\right)$. Reliability for compliance was lower in the first wave for compliance with mothers $\left(\alpha=.68, \omega_{t}=.76\right)$, and in the first three waves for compliance with fathers ( $\alpha \mathrm{s} .64-.67, \omega_{\mathrm{t}} \mathrm{s} .70-.77$ ). In all other waves, reliability of compliance was good ( $\alpha \mathrm{s}$.70-.85, $\left.\omega_{\mathrm{t}} \mathrm{S} .76-.89\right)$.

\section{Strategy of analyses}

We modeled developmental trajectories of empathic dispositions and conflict resolution behaviors using multivariate Latent Growth Curve modeling (Preacher, Wichman, MacCallum, \& Briggs, 2008). Developmental trajectories are modeled using two latent variables: An intercept, which reflects the estimated level of the variable at age 13, and a slope, which reflects the amount of change over time. Because we had no specific hypotheses about the overall shape of developmental trajectories, we estimated the slope factor loadings freely, anchored at the first and last time points. To account for known sex differences in developmental trajectories, we controlled the latent growth parameters for adolescent sex (see Table 1). For the sake of power, we conducted analyses separately for the four conflict behaviors and for conflict with each parent. To address our hypotheses about parallel development, we investigated correlations between the intercepts (level) and slopes (change over time) of the developmental trajectories of empathic concern and perspective taking, and conflict resolution behaviors, displayed in Table 1. See Fig. 1 for the resulting structural equation model. We focused primarily on intercept-intercept and slope-slope correlations, because the interpretation of intercept-slope correlations between variables is complicated if there are also intercept-intercept or slope-slope correlations. If the intercepts of two variables are correlated, and there are negative intercept-slope correlations within variables, there are often also negative intercept-slope correlations between those variables. We used Bayesian model selection to evaluate our inequality-constrained hypotheses that both intercept-intercept and slope-slope correlations with specific conflict behaviors were greater perspective taking than for empathic concern (or vice versa), against the alternative hypothesis that any other order of correlations was true, also known as the hypothesis' complement (van de Schoot, Verhoeven, \& Hoijtink, 2013). The resulting Bayes factors reflect the ratio of the extent to which the data support the hypothesis, rather than its complement. Therefore, $B F>1$ : more support for the hypothesis than for its complement; $B F \approx 1$ : inconclusive; $B F<1$ : more support for the complement of the hypothesis.

\section{Results}

Analyses were conducted using structural equation modeling in MPlus (Muthén \& Muthén, 1998-2012). We made use of Full Information Maximum Likelihood (FIML) estimation, which makes use of all available information, without estimating missing data. Missing data ranged from $0.40 \%$ at age $13-14.50 \%$ at age 18 . Although Little's MCAR test was significant, $\left(\chi^{2}(2610)=3144.61, p<.001\right)$, the $\chi^{2} / \mathrm{df}$ ratio of 1.20 is well within the acceptable range for large samples (Bollen, 2014), and FIML does not assume MCAR. We considered RMSEA $\leq .05$, and CFI $\geq .95$, supplemented by SRMR $\leq .08$, to indicate good fit (Kline, 2011). Fit indices for the resulting models are shown in Table 2.

\section{Mean developmental trajectories of conflict resolution behaviors}

The means and standard deviations of the intercepts and slopes of the multivariate growth models can be found in Table 1. The mean developmental trajectories of empathic concern and perspective taking in this sample have been reported in detail by Van Der Graaff (2014). The mean level of empathic concern was higher than that of perspective taking. Although the average slope of empathic concern was not significant, there was an average increase in perspective taking. In line with previous research, problem solving was the most commonly used conflict resolution behavior with both mothers and fathers. On average, problem solving with mothers increased throughout adolescence, whereas problem solving with fathers remained stable. Withdrawal was the second most commonly used conflict behavior, followed by compliance. On average, withdrawal and compliance with mothers decreased over time, whereas withdrawal and compliance with fathers increased. Finally, conflict escalation was used least often with parents. On average, conflict escalation with mothers decreased over time, whereas escalation with fathers remained stable. 


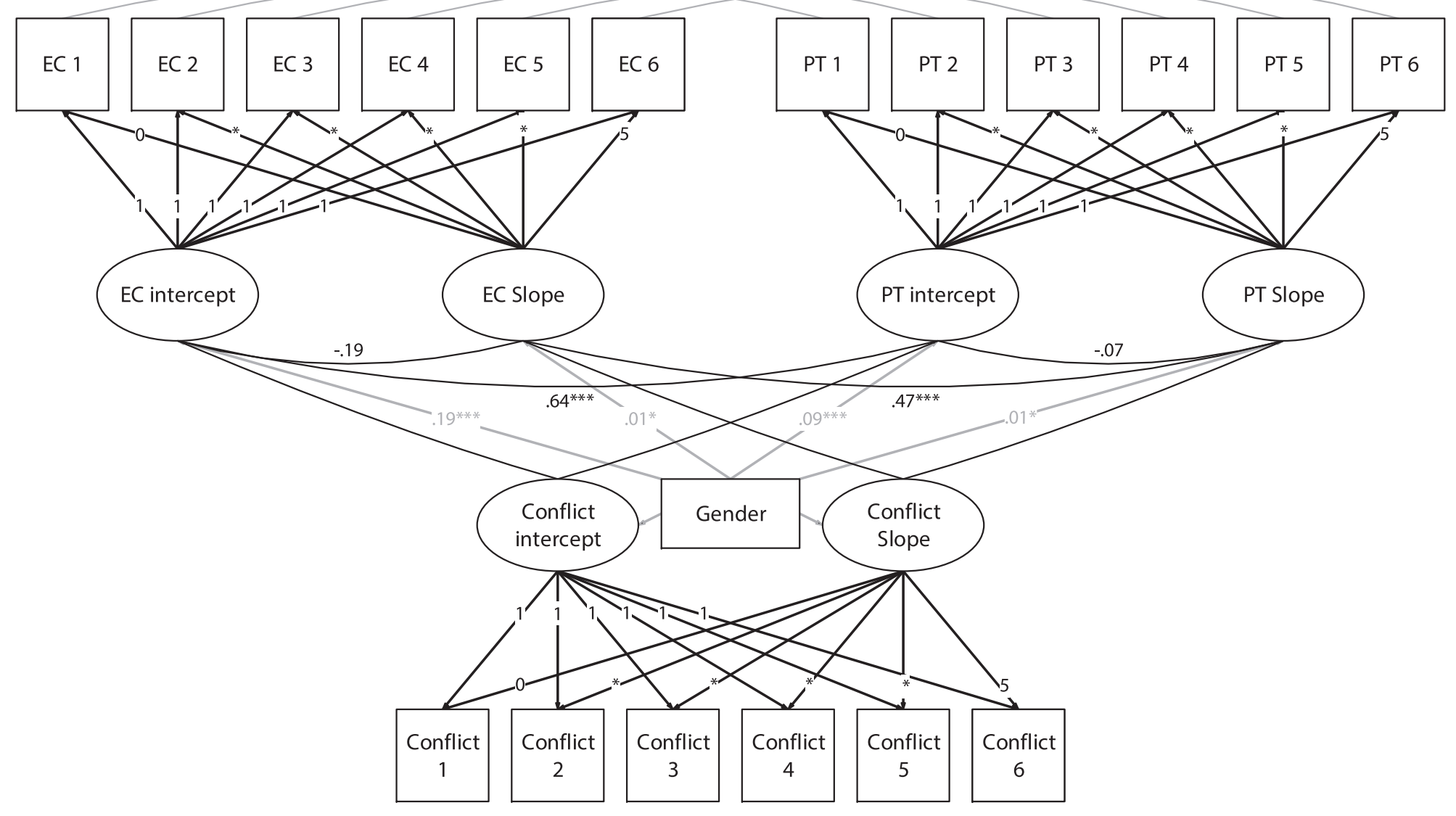

* refers to a freely estimated factor loading. For latent variable correlations, see Table 1. For model fit indices, see Table 2.

Fig. 1. Multivariate latent growth model of adolescents' empathic concern (EC), perspective talking (PT), and conflict resolution behaviour. 
Table 2

Overview of model fit indices.

\begin{tabular}{|c|c|c|c|c|c|c|c|}
\hline Model & $\chi^{2}$ & $\mathrm{df}$ & AIC & $\mathrm{BIC}$ & RMSEA & CFI & SRMR \\
\hline \multicolumn{8}{|c|}{ Conflict resolution with mothers } \\
\hline Engagement & 264.30 & 138 & 10796.53 & 11086.92 & 0.043 & 0.971 & 0.054 \\
\hline Problem solving & 267.11 & 138 & 12350.09 & 12640.48 & 0.043 & 0.971 & 0.061 \\
\hline Compliance & 256.05 & 138 & 10956.48 & 11246.87 & 0.041 & 0.969 & 0.056 \\
\hline Withdrawal & 177.20 & 103 & 10465.98 & 10739.54 & 0.038 & 0.979 & 0.059 \\
\hline \multicolumn{8}{|c|}{ Conflict resolution with fathers } \\
\hline Engagement & 280.68 & 138 & 10524.15 & 10814.54 & 0.046 & 0.968 & 0.059 \\
\hline Problem solving & 252.48 & 138 & 12261.54 & 12551.94 & 0.041 & 0.974 & 0.061 \\
\hline Compliance & 264.27 & 138 & 10759.21 & 11049.61 & 0.043 & 0.966 & 0.058 \\
\hline Withdrawal & 178.24 & 103 & 10216.98 & 10490.54 & 0.038 & 0.978 & 0.058 \\
\hline
\end{tabular}

Developmental links between empathy and conflict resolution behaviors

\section{Conflict escalation}

In partial support of hypotheses, the intercepts of empathic concern and perspective taking were both negatively associated with the intercept of conflict escalation towards mothers. For fathers, only the intercept of perspective taking showed a trending negative association with escalation $(p=.07)$. Furthermore, only the slope of perspective taking was negatively associated with the slope of escalation towards mothers. There were no significant slope-slope correlations for fathers. These results indicate that adolescents with higher levels of empathic concern or perspective taking displayed lower levels of escalation with mothers, and that adolescents with higher perspective taking displayed less escalation with fathers. Moreover, over-time increases in perspective taking were associated with decreasing escalation toward mothers. Although we hypothesized that associations with escalation would be the same for both empathy dimensions, there appeared to be more negative associations with perspective taking than with empathic concern. As a post-hoc comparison, we therefore tested the informative hypothesis that both the intercept-intercept and slope-slope correlations were more negative for perspective taking than for empathic concern against the complementary hypothesis that any other order of parameters was true. For escalation towards mothers, the Bayes factor was $B F=1.63$, indicating that the data provided marginally more support for the hypothesis than for any other ordering of these correlations. For fathers, the data provided twice as much support for this hypothesis than for any other order, $B F=2.30$. These post-hoc comparisons suggest that perspective taking was more negatively associated with escalation than empathic concern.

\section{Problem solving}

We expected that perspective taking would be more positively associated with problem solving than empathic concern. In partial support of hypotheses, intercepts of empathic concern and perspective taking were both positively associated with the intercepts of problem solving with both parents. Furthermore, the slopes of empathic concern and perspective taking were positively associated with the slope of problem solving with both parents. We compared our informative hypothesis that the intercept-intercept and slope-slope correlations were both greater for perspective taking than for empathic concern against the complementary hypothesis that any other order of parameters was true. In line with predictions, for mothers, the Bayes factor was $B F=3.58$, indicating that the data provided three times more support for the hypothesis that correlations were larger for perspective taking than for empathic concern, as compared to any other ordering of these correlations. For fathers, the data provided twice as much support for our hypothesis than for any other order, $B F=2.22$. These findings indicate that the levels and change over time in both empathic dispositions were positively associated with problem solving toward both parents, but also that these associations were stronger for perspective taking than empathic concern.

\section{Compliance}

We did not find the hypothesized intercept-intercept and slope-slope associations between empathic dispositions and compliance with either parent. However, the intercept of compliance with mothers was positively correlated with the slope of empathic concern. The interpretation of this particular intercept-slope correlation is straightforward, because of the absence of any other correlations between adolescents' empathic dispositions and compliance with mothers. High levels of compliance with mothers at age 13 were associated with over-time increasing empathic concern. For fathers, we found a trending association between the slope of perspective taking and compliance $(r=.22, p=.06)$, suggesting that increasing perspective taking was associated with increasing compliance with fathers.

\section{Withdrawal}

In contrast to previous research, we did not find that empathic concern was positively related to withdrawal. Instead, we found that the intercept of perspective taking was negatively associated with the intercepts of withdrawal from both parents. This indicates that adolescents higher in perspective taking withdrew less frequently from conflicts with both parents. We compared our informative hypothesis that both the intercept-intercept and slope-slope correlations were more positive for empathic concern than for perspective taking against the complementary hypothesis that any other order of these 
parameters was true. In partial support of our hypothesis, the Bayes factor was $B F=9.39$ for withdrawal from mothers. For withdrawal from fathers, $B F=1.00$, which is inconclusive.

\section{Discussion}

The purpose of the present study was to examine whether the development of adolescents' empathic concern and perspective taking is paralleled by changes in their conflict behaviors towards parents. In partial support of hypotheses, we found that both empathic dispositions had common negative associations with escalation, and positive associations with problem solving. In addition to these common associations, however, we also found evidence for unique associations with conflict escalation and problem solving. Specifically, associations with escalation and problem solving were consistently stronger for perspective taking than for empathic concern. Thus, although we found support for common associations of both empathy dimensions with reduced escalation and increased problem solving, these associations were greater across the board for perspective taking than for empathic concern. Counter to hypotheses, we did not find evidence for parallel development of empathic concern and compliance. Instead, we found that higher levels of compliance with mothers at age 13 were associated with increasing empathic concern over time. Finally, although we hypothesized that empathic concern would be positively associated with withdrawal, we instead found that perspective taking was negatively associated with withdrawal from conflict with both parents. These findings, combined with the asymmetrical strength of the associations with escalation and problem solving, suggest that perspective taking is more strongly associated with a tendency to address conflict with parents in a constructive and egalitarian way, rather than simply withdrawing from conflict or complying with parents' desires.

Our results thus provided evidence for both common and unique associations of empathic concern and perspective taking with specific conflict behaviors. Results were largely in line with hypotheses, although not all specific predictions about unique associations for empathic concern and perspective taking were supported. For example, we predicted that developmental trajectories of empathic concern would be positively associated with the parallel development of compliance. Instead, we found that early levels of compliance with mothers were associated with increasing empathic concern over time. This discrepancy might be related to the fact that our hypothesis was based on prior cross-sectional research, which reflects only within-time associations, and therefore could not have supported hypotheses pertaining to developmental order. Our findings suggest that associations between compliance and empathic concern may emerge over time, as opposed to through parallel development. Although post-hoc interpretations are speculative, this finding may suggest that the practice of mitigating conflicts with mothers through compliance might reinforce adolescents' tendency to put their concern for others before their self-interest. We also predicted that empathic concern would be positively associated with withdrawal, but this association was not present. Instead, we found that perspective taking was negatively associated with withdrawal. Several factors might contribute to this unexpected result. First of all, prior research examining empathy and withdrawal in adolescents did not account for potential links with perspective taking (Björkqvist et al., 2000; De Wied et al., 2007). Secondly, these studies used measures of affective empathy that tapped into the tendency to share others' emotions, as well as the tendency to experience sympathetic empathic concern for others' emotions. Shared empathic emotions can be aversive, and sometimes evoke a tendency to avoid the source of those emotions (Eisenberg, 2000). This might explain the link between affective empathy and withdrawal found in previous research.

Prior research has indicated that, in adolescence, developmental changes in empathy parallel a shift in adolescents' conflict behaviors towards parents (Laursen et al., 2001; Van der Graaff et al., 2014; Van Doorn, Branje, \& Meeus, 2011; Van Doorn, Branje, Van der Valk, et al., 2011). The present research extends previous correlational and experimental findings to a developmental context, and suggests that, within adolescents, empathy development is associated with a shift towards more constructive and egalitarian conflict behaviors. Moreover, our findings suggest that perspective taking was more strongly associated with a shift towards constructive conflict resolution than empathic concern. This is relevant for interventions that aim to promote adolescents' empathy development and constructive conflict behavior. Specifically, our research suggests that such interventions might focus primarily on promoting adolescents' perspective taking development. Interventions focusing on perspective taking might also be more effective, as prior research has suggested that perspective taking is particularly susceptible to developmental influences in adolescence (Van Lissa et al., 2014).

There were notable differences in the pattern of results between mothers and fathers. For example, higher levels of both empathic dispositions were significantly associated with lower levels of conflict escalation with mothers, but not with fathers. These findings can be interpreted in the context of known qualitative differences between adolescents' relationships with mothers and fathers. Relationships with mothers have been described as more "intense" than relationships with fathers (Steinberg \& Silk, 2002). This intensity is reflected in by the fact that adolescent-mother relationships are, on the one hand, characterized by more frequent and intense conflict, and on the other hand, by greater support and expressed emotion (Branje et al., 2013; De Goede et al., 2009; Steinberg \& Silk, 2002). Maternal support has been shown to predict empathy development in adolescents (Miklikowska, Duriez, \& Soenens, 2011). If negative emotions are expressed in a supportive relationship context, they might be more likely to trigger empathic responses, which in turn might help to de-escalate the conflict. Thus, links between empathy and escalation might be stronger in adolescent-mother relationships, because conflict, support, and expressed emotion go hand in hand to a greater extent in adolescent-mother relationships than in adolescent-father relationships. Secondly, higher levels of compliance with mothers - but not with fathers - were associated with increasing empathic concern over time. As we mentioned before, relationships with mothers are typically closer and 
more supportive than with fathers (Steinberg \& Silk, 2002). Consequently, adolescents might be more concerned for mothers' emotional well-being, and comply with mothers out of sympathy. This could explain why the link between compliance and empathic concern was stronger in adolescent-mother relationships than adolescent-father relationships.

One clear limitation of the present study is the correlational nature of the data, which precludes making causal inferences about the direction of effects. However, the present multivariate growth curve approach is the most appropriate test for parallel development, because it reveals the extent to which change in empathic dispositions and conflict behaviors is associated within individuals. Previous empirical work demonstrated that experimentally induced empathy promotes prosocial conflict behavior in bogus interactions (e.g., Galinsky et al., 2008; Richardson et al., 1994), and future research might replicate these findings in adolescent-parent conflict interactions.

Another limitation is that all variables were measured using adolescent self-reports. Consequently, common method bias might provide an alternative explanation for associations between these variables (Podsakoff, MacKenzie, Lee, \& Podsakoff, 2003). Moreover, perspective taking might have stronger associations with conflict behavior than empathic concern because items of the perspective taking subscale appear to suggest a context of conflict (e.g., "I try to look at everybody's side of a disagreement before I make a decision"). Consequently, these questions might tap into similar self-theories as the questions regarding conflict behaviors. Nevertheless, a strong argument in favor of using self-report measures to assess empathic dispositions is that empathy is an internal process, which might not necessarily be expressed in overt behavior. Indeed, research indicates that parents' estimates of adolescents' empathy correlate poorly with adolescents' reports (Cliffordson, 2001). Because conflict resolution behavior is more readily observable, however, future research could include third party reports of adolescents' conflict resolution behavior, or even code observations of behavior in actual adolescent-parent conflicts. Parents' reports about adolescents' conflict behavior might be biased, however, if parents are themselves involved in the conflict.

Another limitation is related to the operationalization of empathy. Empathy has historically been defined in myriad ways (Batson, 2009). Although the present research contributes to prior literature on empathy and conflict resolution by incorporating measures of both affective and cognitive empathy dimensions, the empathic concern and perspective taking subscales of the IRI do not capture all aspects of these empathy dimensions. Most notably, researchers have argued that pure empathy refers to sharing others' emotions, whereas other-oriented feelings of caring are more appropriately referred to as sympathy (Eisenberg, 2000). The empathic concern scale used in the present study is purported to measure only dispositional sympathy. Future research might thus address the role of shared emotions in adolescent-parent conflict resolution. Finally, a minor limitation of the present study is that the IRI assesses individuals' general tendencies to engage in empathic concern and perspective taking, and does not measure their specific responses toward their parents. Adolescents' empathic responses in specific situations - such as conflict with parents - could differ from their general empathic dispositions. Future research might therefore address the role of situational empathy in conflicts with parents.

Despite these limitations, the present research advances our understanding of the links between empathy and conflict resolution behavior. This study is the first to investigate the parallel development of empathic concern and perspective taking with conflict resolution behaviors towards both parents throughout adolescence. Prior experimental work has demonstrated that affective and cognitive empathy dimensions hold common and unique associations with particular conflict behaviors in bogus interactions (Galinsky et al., 2008; Richardson et al., 1994). The present study builds upon these findings, by showing that adolescents' naturally occurring development is accompanied by similar changes in conflict behavior towards parents. Our longitudinal approach improves upon previous research examining adolescents' empathy and conflict resolution behavior, which has been mostly cross-sectional, and has failed to address unique associations of empathic concern and perspective taking (Björkqvist et al., 2000; De Wied et al., 2007). Our results suggest that adolescents' developing perspective taking is more strongly associated with a pattern of increasing constructive and egalitarian conflict resolution behaviors towards parents than empathic concern. Interestingly, perspective taking also appears to be the empathy dimension most susceptible to developmental influences in adolescence (Van Lissa et al., 2014). Therefore, interventions focusing on perspective taking might be most beneficial in promoting adolescents' constructive conflict resolution behavior.

\section{Authors' contributions}

CJ conceived of the study, conducted the analyses and drafted the manuscript; SH wrote the grant proposal and supervised the analyses and manuscript writing; SB participated in the design of the longitudinal study and gave feedback on each version of the manuscript; HK participated in the design of the longitudinal study and gave feedback on the manuscript; WM participated in the design of the longitudinal study and supervised the analyses and manuscript writing. All authors read and approved the final manuscript.

\section{Acknowledgments}

Data of the RADAR study were used. RADAR has been financially supported by main grants from the Netherlands Organisation for Scientific Research (GB-MAGW 480-03-005, GB-MAGW 480-08-006), and Stichting Achmea Slachtoffer en Samenleving (SASS), and various other grants from the Netherlands Organisation for Scientific Research, the VU University Amsterdam and Utrecht University. 


\section{References}

Adams, R., \& Laursen, B. (2001). The organization and dynamics of adolescent conflict with parents and friends. Journal of Marriage and Family, 63(1), 97-110. http://dx.doi.org/10.1111/j.1741-3737.2001.00097.x.

Batson, C. D. (2009). These things called empathy: eight related but distinct phenomena. In J. Decety, \& W. J. Ickes (Eds.), The social neuroscience of empathy (p. 3). Cambridge, Mass: MIT Press.

Batson, C. D., \& Ahmad, N. (2001). Empathy-induced altruism in a prisoner's dilemma II: what if the target of empathy has defected? European Journal of Social Psychology, 31(1), 25-36.

Björkqvist, K., Österman, K., \& Kaukiainen, A. (2000). Social intelligence - empathy = aggression? Aggression and Violent Behavior, 5(2), 191-200.

Blair, R. J. R. (2004). The roles of orbital frontal cortex in the modulation of antisocial behavior. Brain and Cognition, 55(1), 198-208. doi http://dx.doi.org/10. 1016/S0278-2626(03)00276-8.

Bollen, K. A. (2014). Structural equations with latent variables. John Wiley \& Sons.

Branje, S. J. T., Van Doorn, M. D., Van der Valk, I. E., \& Meeus, W. (2009). Parent-adolescent conflicts, conflict resolution types, and adolescent adjustment. Journal of Applied Developmental Psychology, 30(2), 195-204. http://dx.doi.org/10.1016/j.appdev.2008.12.004.

Branje, S. J. T., Laursen, B., \& Collins, W. A. (2013). In A. L. Vangelisti (Ed.), Parent-child communication during adolescence (2nd ed., pp. 271-286). New York, NY: Routledge.

Choudhury, S., Blakemore, S., \& Charman, T. (2006). Social cognitive development during adolescence. Social Cognitive and Affective Neuroscience, 1(3), 165-174. http://dx.doi.org/10.1093/scan/nsl024.

Chow, C. M., Ruhl, H., \& Buhrmester, D. (2013). The mediating role of interpersonal competence between adolescents' empathy and friendship quality: a dyadic approach. Journal of Adolescence, 36(1), 191-200.

Cliffordson, C. (2001). Parents' judgments and students' self-judgments of empathy: the structure of empathy and agreement of judgments based on the interpersonal reactivity index (IRI). European Journal of Psychological Assessment, 17(1), 36-47. http://dx.doi.org/10.1027//1015-5759.17.1.36.

Davis, M. H. (1983). Measuring individual differences in empathy: evidence for a multidimensional approach. Journal of Personality and Social Psychology, 44(1), 113-126. http://dx.doi.org/10.1037/0022-3514.44.1.113.

De Corte, K., Buysse, A., Verhofstadt, L., Roeyers, H., Ponnet, K., \& Davis, M. (2007). Measuring empathic tendencies : reliability and validity of the dutch version of the interpersonal reactivity index. Psychologica Belgica, 47(4), 235-260.

De Goede, I., Branje, S., \& Meeus, W. (2009). Developmental changes in adolescents' perceptions of relationships with their parents. Journal of Youth and Adolescence, 38(1), 75-88. http://dx.doi.org/10.1007/s10964-008-9286-7.

De Wied, M., Branje, S. J. T., \& Meeus, W. (2007). Empathy and conflict resolution in friendship relations among adolescents. Aggressive Behavior, 33(1), 48-55. http://dx.doi.org/10.1002/ab.20166.

Eisenberg, N. (2000). Empathy and sympathy. (987).

Eisenberg, N., Cumberland, A., Guthrie, I. K., Murphy, B. C., \& Shepard, S. A. (2005). Age changes in prosocial responding and moral reasoning in adolescence and early adulthood. Journal of Research on Adolescence, 15(3), 235-260. http://dx.doi.org/10.1111/j.1532-7795.2005.00095.x.

Eisenberg, N., \& Miller, P. A. (1987). The relation of empathy to prosocial and related behaviors. Psychological Bulletin, 101(1), 91-119. http://dx.doi.org/10. 1037/0033-2909.101.1.91.

Eisenberg, N., Spinrad, T. L., \& Sadovsky, A. (2006). Empathy-related responding in children. In M. Killen, \& J. G. Smetana (Eds.), Handbook of moral development. (pp. 517-549). Mahwah, NJ, US: Lawrence Erlbaum Associates Publishers.

Feshbach, N. D., \& Feshbach, S. (2011). Empathy and education. In J. Decety, \& W. J. Ickes (Eds.), The social neuroscience of empathy (pp. 85-97). Cambridge, Massachusetts: MIT Press.

Frith, C. D., \& Frith, U. (2006). The neural basis of mentalizing. Neuron, 50(4), 531-534. doi http://dx.doi.org/10.1016/j.neuron.2006.05.001.

Galinsky, A. D., Maddux, W. W., Gilin, D., \& White, J. B. (2008). Why it pays to get inside the head of your opponent. Psychological Science, 19(4), 378-384. http://dx.doi.org/10.1111/j.1467-9280.2008.02096.x.

Gee, D. G., Humphreys, K. L., Flannery, J., Goff, B., Telzer, E. H., Shapiro, M., et al. (2013). A developmental shift from positive to negative connectivity in human amygdala-prefrontal circuitry. The Journal of Neuroscience : The Official Journal of the Society for Neuroscience, 33(10), 4584-4593. http://dx.doi. org/10.1523/JNEUROSCI.3446-12.2013.

Hawk, S. T., Keijsers, L., Branje, S. J., Van der Graaff, J., Wied, M.d., \& Meeus, W. (2013). Examining the interpersonal reactivity index (IRI) among early and late adolescents and their mothers. Journal of Personality Assessment, 95(1), 96-106.

Kline, R. B. (2011). Principles and practice of structural equation modeling. New York: Guilford Press.

Kurdek, L. A. (1994). Conflict resolution styles in gay, lesbian, heterosexual nonparent, and heterosexual parent couples. Journal of Marriage and the Family, $705-722$.

Laursen, B. (1995). Conflict and social interaction in adolescent relationships. Journal of Research on Adolescence, 5(1), 55-70.

Laursen, B., \& Collins, W. A. (2004). Parent-child communication during adolescence. In A. L. Vangelisti (Ed.), Handbook of family communication (pp. 333-348). New Jersey: Lawrence Erlbaum Associates.

Laursen, B., Finkelstein, B. D., \& Betts, N. T. (2001). A developmental meta-analysis of peer conflict resolution. Developmental Review, 21 (4), 423-449.

Van Lissa, C. J., Hawk, S. T., de Wied, M., Koot, H. M., van Lier, P., \& Meeus, W. (2014). The longitudinal interplay of affective and cognitive empathy within and between adolescents and mothers. Developmental Psychology, 50(4), 1219-1225. http://dx.doi.org/10.1037/a0035050.

Markiewicz, D., Lawford, H., Doyle, A. B., \& Haggart, N. (2006). Developmental differences in adolescents' and young adults' use of mothers, fathers, best friends, and romantic partners to fulfill attachment needs. Journal of Youth and Adolescence, 35(1), 121-134.

Miklikowska, M., Duriez, B., \& Soenens, B. (2011). Family roots of empathy-related characteristics: the role of perceived maternal and paternal need support in adolescence. Developmental Psychology, 47(5), 1342-1352. http://dx.doi.org/10.1037/a0024726.

Miller, P. A., \& Eisenberg, N. (1988). The relation of empathy to aggressive and externalizing/antisocial behavior. Psychological Bulletin, 103(3), 324-344.

Muthén, L. K., \& Muthén, B. O. (1998-2012). Mplus user's guide (7th ed.). Los Angeles, CA: Muthén \& Muthén.

Podsakoff, P. M., MacKenzie, S. B., Lee, J., \& Podsakoff, N. P. (2003). Common method biases in behavioral research: a critical review of the literature and recommended remedies. Journal of Applied Psychology, 88(5), 879-903. http://dx.doi.org/10.1037/0021-9010.88.5.879.

Preacher, K. J., Wichman, A. L., MacCallum, R. C., \& Briggs, N. E. (2008). Latent growth curve modeling. Thousand Oaks, CA: Sage Publications.

Revelle, W., \& Zinbarg, R. E. (2009). Coefficients alpha, beta, omega, and the glb: comments on sijtsma. Psychometrika, 74(1), 145-154.

Richardson, D. R., Hammock, G. S., Smith, S. M., Gardner, W., \& Signo, M. (1994). Empathy as a cognitive inhibitor of interpersonal aggression. Aggressive Behavior, 20(4), 275-289. http://dx.doi.org/10.1002/1098-2337(1994)20:43.0.CO;2-4.

Rubenstein, J. L., \& Feldman, S. S. (1993). Conflict-resolution behavior in adolescent boys: antecedents and adaptational correlates. Journal of Research on Adolescence, 3(1), 41-66. http://dx.doi.org/10.1207/s15327795jra0301 \_3.

Sandy, S. V., \& Cochran, K. M. (2000). The development of conflict resolution skills in children: preschool to adolescence. In M. Deutsch, \& P. T. Coleman (Eds. ), The handbook of conflict resolution: Theory and practice (pp. 316-342). San Francisco, CA, US: Jossey-Bass.

van de Schoot, R., Verhoeven, M., \& Hoijtink, H. (2013). Bayesian evaluation of informative hypotheses in SEM using M plus: a black bear story. European Journal of Developmental Psychology, 10(1), 81-98. http://dx.doi.org/10.1080/17405629.2012.732719.

Silberman, M. A., \& Snarey, J. (1993). Gender differences in moral development during early adolescence: the contribution of sex-related variations in maturation. Current Psychology, 12(2), 163-171.

Singer, T. (2006). The neuronal basis and ontogeny of empathy and mind reading: review of literature and implications for future research. Neuroscience \& Biobehavioral Reviews, 30(6), 855-863. http://dx.doi.org/10.1016/j.neubiorev.2006.06.011. 
Smetana, J. G., Daddis, C., \& Chuang, S. S. (2003). "Clean your room!” A longitudinal investigation of adolescent-parent conflict and conflict resolution in middle-class African American families. Journal of Adolescent Research, 18(6), 631-650.

Statistics-Netherlands. (1993). Standaard beroepenclassificatie 1992 [standardized classification of occupations 1992]. Voorburg/Heerlen: Netherlands Central Bureau of Statistics.

Steinberg, L., \& Silk, J. S. (2002). Parenting adolescents. Handbook of Parenting, 1, 103-133.

Stocks, E. L., Lishner, D. A., \& Decker, S. K. (2009). Altruism or psychological escape: why does empathy promote prosocial behavior? European Journal of Social Psychology, 39(5), 649-665. http://dx.doi.org/10.1002/ejsp.561.

Van Doorn, M. D., Branje, S. J. T., \& Meeus, W. H. J. (2008). Conflict resolution in parent-adolescent relationships and adolescent delinquency. The Journal of Early Adolescence, 28(4), 503-527. http://dx.doi.org/10.1177/0272431608317608.

Van Doorn, M. D., Branje, S. J. T., \& Meeus, W. H. J. (2011). Developmental changes in conflict resolution styles in parent-adolescent relationships: a fourwave longitudinal study. Journal of Youth and Adolescence, 40(1), 97-107. http://dx.doi.org/10.1007/s10964-010-9516-7.

Van Doorn, M. D., Branje, S. J. T., Van der Valk, I. E., De Goede, I. H. A., \& Meeus, W. H. J. (2011). Longitudinal spillover effects of conflict resolution styles between adolescent-parent relationships and adolescent friendships. Journal of Family Psychology, 25(1), 157-161. http://dx.doi.org/10.1037/a0022289.

Van Lier, P. A. C., Frijns, T., Neumann, A., Den Exter Blokland, E., Koot, H. M., \& Meeus, W. (2015). The RADAR young study: Design, description of sample, and validation of cohort assignment (unpublished manuscript).

Van der Graaff, J., De Wied, M., Hawk, S. T., Van Lier, P., \& Meeus, W. (2014). Perspective taking and empathic concern in adolescence: gender differences in developmental changes. Developmental Psychology, 50(3), 881-888. http://dx.doi.org/10.1037/a0034325.

Vuchinich, S. (1987). Starting and stopping spontaneous family conflicts. Journal of Marriage and the Family, 49(3), 591-601. http://dx.doi.org/10.2307/ 352204. 